\title{
Preparation of diagnostic ELISA kits for detection of camelpox virus
}

\author{
E. A. Aboul Soud', Magda, M. Sayed ${ }^{2}$, A. A. Badawi', M. M. Taha', \\ Elham A. El-Ebiary ${ }^{2}$, A. M. Daoud \\ ${ }^{1}$ Veterinary Serum and Vaccine Research Institute, Abbassia, Cairo, Egypt \\ ${ }^{2}$ Central Laboratory for Evaluation of Veterinary Biologics, Abbasia, Cairo, Egypt
}

\begin{abstract}
Peroxidase labeled immunoglobulins to camelpox virus (CPV) were prepared for use in various techniques of ELISA. Ten rabbits and three goats were inoculated with a mixture of camelpox virusand Freund's adjuvant. Sera were pooled separately on the $10^{\text {th }}$ day post the last inoculation and immunoglobulins were precipitated using saturated ammonium sulphate. The globulins were $2.8 \mathrm{~g} / \mathrm{dl}$ and $2.5 \mathrm{~g} / \mathrm{dl}$ for rabbits and goats respectively and used for peroxidase conjugation. The peroxidase labeled immunoglobulins were titrated and evaluated using direct solid phase ELISA, double antibody sandwich ELISA and dot immunoblot ELISA. The prepared conjugates gave specific and clear positive reactions till the dilution of 2000 and 1500 for rabbits and goats immunoglobulins respectively. The prepared labeled immunoglobulins could be successfully used in detection of camel pox viral antigen of local virulent and standard vaccinal strain of the virus using various ELISA techniques.
\end{abstract}

Camelpox disease (CPD) is an orthopox virus that causes one of the most common important contagious skin diseases of camels (Munz 1992).

The disease is characterized by fever, swollen lymph nodes and skin lesions in the form of macule, papule, vesicle, pustule and scab formation (Warnery et al., 1997).

In Egypt, camelpox virus was isolated for the first time from infected camels and the isolated virus was propagated in embryonated chicken eggs (ECE) (Tantawi et al., 1973). Diagnosis of CPD depends on clinicopathological examination, virus isolation either in tissue culture (TC) or in ECE and virus identification by electron microscope (Khanna et al., 1996; Munz et al., 1997; Maysa et al., 1998; El-Harrak and Loutfi, 2000 and Tefera and Gabreah, 2001). Sero-diagnosis using enzyme linked immunosorbent assay (ELISA) was used for screening the antibodies and virus infections in dromedaries (Munz et al., $1986 \mathrm{a}, \mathrm{b}$ ).

Application of ELISA for diagnosis of CPD either by detection of viral antigen or antibodies was hardly to do as patent camel kits are not commercially available, so, the investigation of CPV antigens and sera of camels by ELISA necessitates some modification of the technique such as using rabbit anti-CPV antibodies and a patent kit of anti-rabbit peroxidase conjugate (Munz, 1986 a, b and El-Said, 2001).
The aim of this study lies on detection of CP viral antigen and antibodies in infected camels by preparing cheap ELISA kit with purified peroxidase labeled polyclonal immunoglobulins specific for CPV in rabbits and goats.

\section{Material and Methods}

Animals. Ten apparently healthy adult male New Zealand rabbits (three months old) and three goats (one year old) were inoculated with reference vaccinal strain of CPV emulsified with complete and incomplete Freund's adjuvants.

\section{Viruses.}

a) Vaccinal strain of camelpox virus.

Attenuated camelpox virus vaccine was kindly supplied by Pox Department, Veterinary Serum and Vaccine Research Institute (VSVRI), Abbasia, Cairo. It was propagated and titrated in Vero cells and has a titre of $5.8 \log _{10} \mathrm{TCID}_{50} / \mathrm{ml}$ (El-Said, 2001). It was used for preparing the hyperimmune sera in rabbits and goats as well as a positive control antigen.

b) Egyptian field strains of camelpox virus.

Fayoum strain of CPV was isolated (Tantawi et al., 1973) and received from Virology Department, Faculty of Veterinary Medicine, Cairo University. It was propagated on chorioallantoic membrane (CAM) in ECE and has a titre of 5 $\log _{10} \mathrm{EID}_{50} / \mathrm{ml}$. Marsamatroh strain of CPV (Maysa et al., 1998) was isolated at Animal Health Research Institute, Dokki, and Giza. It was adapted in Vero cell cultures and has a titre 
of $5.4 \log _{10} \mathrm{TCID}_{50} / \mathrm{ml}$ (Gabry et al., 2003). Aswan strain of CPV was passed on CAM of ECE in Pox Department, VSVRI, Abbasia, and Cairo and has a titre of $5.5 \log _{10} \mathrm{EID}_{50} / \mathrm{ml}$ (ElSaid, 2001). These isolates were prepared as viral antigens for evaluating the prepared peroxidase labeled antibodies using various techniques of ELISA.

Reference camel hyperimmune serum against CPV. It was received from Virology Department, Faculty of Veterinary Medicine, Cairo University. It has a titre of 128 and used in double antibody sandwich ELISA (El-Said, 2001).

Preparation of anti-camelpox virus hyperimmune sera. Preparation of polyclonal antibodies in rabbits and goats against CPV was performed according to the method described by Munz et al. (1986 a, b).

Serum neutralization test (SNT). It was conducted according to the method described by Martin et al, (1975) and used for titration of the CPV antisera prepared in rabbits and goats.

Precipitation and purification of the prepared immunoglobulins. Anti CPV immunoglobulins prepared in rabbits and goats sera were precipitated using saturated ammonium sulphate solution according to the method described by (Vogt, 1969). Precipitation process was repeated till complete removal of albumin content and the remaining sulphate was removed from the precipitated globulins by dialysis against $0.15 \mathrm{M}$ $\mathrm{NaCl}$.

Conjugation of anti-CPV immunoglobulins with horseradish peroxidase (HRPO): The peroxidase method of conjugation was conducted according to the method described by (Nakane and Kawaoi, 1974; Wilson and Nakane, 1978 and Tijssen and Kurstak, 1984). 10 mg of HRPO were dissolved in $2 \mathrm{ml}$ distilled water then $0.4 \mathrm{ml}$ of freshly prepared sodium periodate solution was added with gentle stirring for 20 minutes at room temperature. The mixture should turn greenish brown and $\mathrm{pH}$ of the solution was raised to 9.5 by adding of $50 \mu \mathrm{l}$ of $0.2 \mathrm{M} \mathrm{Na} \mathrm{Na}_{2} \mathrm{Co}_{3}$. The concentration of anti-CPV globulins prepared in rabbits and goats were adjusted to be $18 \mathrm{mg} / \mathrm{ml}$ in $0.01 \mathrm{M} \mathrm{Na}_{2} \mathrm{Co}_{3}$ and $2 \mathrm{ml}$ of these immunoglobulins were added separately to the mixture. The $\mathrm{pH}$ should be 9.5 and each mixture composed of globulins, HRPO and periodate were then shaked for 2 hours at room temperature. $0.2 \mathrm{ml}$ of $4 \mathrm{mg} / \mathrm{ml}$ sodium borohydride was added and the reaction was allowed to continue for 2 hours at $4^{\circ} \mathrm{C}$. The prepared solution was dialyzed against phosphate buffer saline solution (PBS) and stored after the addition of equal value of glycerol at $-20^{\circ} \mathrm{C}$.

Preparation of partially purified soluble viral antigens (PPSVA) of CPV. Vaccinal strain and local Egyptian CPV isolates were prepared and concentrated as described by (Engval and Perlmann, 1971) to be used as purified antigens in various ELISA techniques.

Titration and evaluation of rabbits and goats anti-CPV peroxidase conjugates. Rabbits and goats anti-CPV labeled immunoglobulins were titrated using reference vaccinal strain of CPV antigen according to the method described by (Engval and Perlmann, 1972). Serial dilutions of either conjugates were prepared separately from $1 / 500$ to $1 / 3000$ using PBS and Tween 20. The titre was calculated as the last dilution of conjugate that gave observable colour with OPD substrate working solution.

Direct solid phase ELISA. It was done according to (Kadden et al., 1992) using the locally prepared rabbits and goats anti-CPV peroxidase conjugates for detection of Egyptian field camelpox virus isolates. Reference CPV vaccinal strain was used as positive control antigen.

Double antibody sandwich ELISA. It was conducted according to (Munz et al., (1986 b) and Johan and Czerny, 1993). In this technique ELISA plates were coated with reference camel anti-CPV hyperimmune serum and local isolates of CPV captured between the reference serum and the prepared rabbits and goats anti-CPV peroxidase conjugates.

Dot immunoblot ELISA. It was applied according to procedures described by (Azwai et al., 1996). In this technique, each CPV antigen of field isolates was doted on a nitrocellulose membrane and identified by using the locally prepared peroxidase conjugates and 4-chloro-1 naphthal substrate solution.

\section{Results and Discussion}

The present work was designed to prepare peroxidase conjugated polyclonal antibodies against a standard vaccinal strain of camelpox virus in rabbits and goats for using in ELISA assays especially a patent ELISA kits that are not commercially available to provide a specific local reagent for rapid identification of CPV.

The developed anti-CPV neutralizing antibody titres of rabbits and goats were 128 and 64 respectively. The obtained antibodies titres were considered high since the protective 
Table (1): Titration and standardization of rabbits and goats peroxidase labeled camelpox virus antibodies.

\begin{tabular}{cccc}
\cline { 2 - 3 } $\begin{array}{c}\text { Conjugate } \\
\text { dilution }\end{array}$ & \multicolumn{2}{c}{ AV of conjugates with CPV (1/20) } & \multirow{2}{*}{ Negative antigen } \\
\cline { 2 - 3 } $\mathbf{1 / 5 0 0}$ & 1.200 & Conjugate (2) & 0.220 \\
$\mathbf{1 / 1 0 0 0}$ & 0.900 & 0.990 & 0.215 \\
$\mathbf{1 / 1 5 0 0}$ & $0.850^{*}$ & 0.800 & 0.225 \\
$\mathbf{1 / 2 0 0 0}$ & $0.820^{*}$ & 0.600 & 0.220 \\
$\mathbf{1 / 2 5 0 0}$ & 0.650 & 0.500 & 0.210 \\
$\mathbf{1 / 3 0 0 0}$ & 0.400 & 0.300 & 0.220 \\
\hline AV: Absorbance Value (492nm) & \multicolumn{3}{c}{ CPV : camelpox virus antigen } \\
Conjugate (1) : Rabbit anti-CPV peroxidase conjugate & Conjugate (2): Goats anti-CPV peroxidase conjugate \\
* The highest readings $=$ The highest dilutions gave observed colour.
\end{tabular}

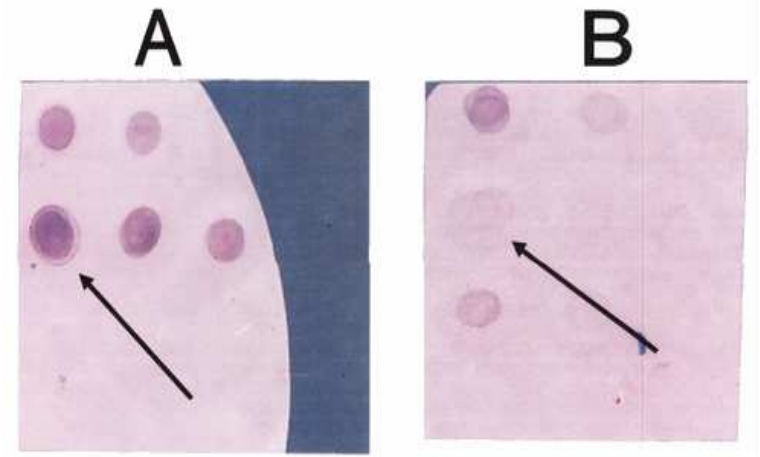

Fig. (2): Dot immunoblot ELISA, the arrow denotes the positive reaction of camelpox viruses with rabbits (A) and goats (B) labeled peroxidase conjugates.

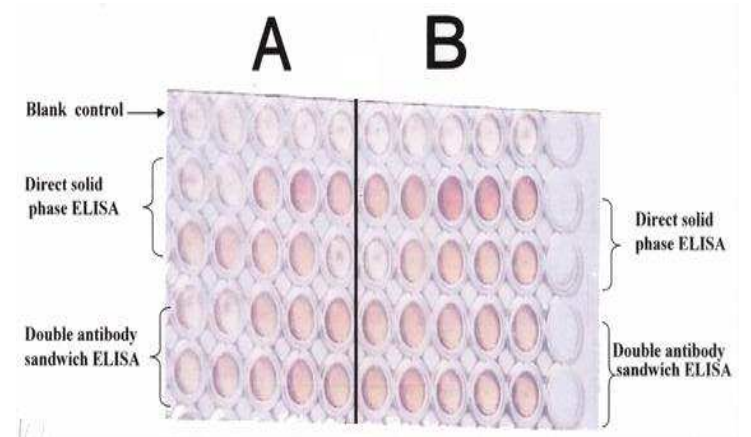

Fig. (1): Direct solid phase and double antibody sandwich ELISA, the brownish Colouration denote to the positive reactions of camelpox viruses with rabbits (A) and goats (B) labeled peroxidase conjugates. neutralizing antibody titre against CPV was 32 or $1.5 \log _{10}$ (Hafez, 1986, Kadden et al., 1992 and El-Said, 2001).

The hyperimmune sera were subjected to a series of precipitation with saturated and half saturated ammonium sulphate till complete removal of albumin content as the globulins reaching the highest values $(2.8 \mathrm{~g} / \mathrm{dl}$ and 2.5 $\mathrm{g} / \mathrm{dl}$ ) for rabbits and goats anti-CPV sera respectively. The prepared globulins were considered enough for conjugation with HRPO especially the standard amount to be used for conjugation was adjusted to be $18-20 \mathrm{mg} / \mathrm{ml}$ (Narin, 1969 and Vogt, 1969).

Titration and standardization of the prepared peroxidase labeled immunoglobulins revealed that the highest dilutions gave observable colour were $1 / 2000$ and $1 / 1500$ for rabbits and goats peroxidase conjugates respectively (Table 1 ). The obtained titres of rabbits and goats anti-CPV conjugates denote the activity and validity of both conjugates that confirmed by the previous reports (Nakane and Kawaoi, 1974; Tijssen and Kurstak, 1984; Saad et al., 2001 and El-Kabbany et al., 2002) who reported that the optimal conjugate dilution by peroxidase method was $1 / 2000$. They added that the periodate treatment of the enzyme does not interfere with its enzymatic or antibody activities. The method depends on oxidation of the carbohydrate of the enzyme with sodium periodate forming aldehyde groups which react readily with primary amino groups in the antibodies. The addition of sodium borohydride is needed to stabilize the complex but will not interfere with the enzymatic or antibodies activities. Moreover, the highest percentage of oxidized enzyme $(70 \%)$ can be found and $99 \%$ of the immunoglobulins are label.

Application of direct solid phase ELISA, double antibody sandwich ELISA and dot immunoblot proved the validity and efficacy of the locally prepared peroxidase labeled immunoglobulins for rapid and accurate detection of vaccinal and field strains of CPV (photos $1 \& 2$ ).

These viruses were previously detected and evaluated using electron microscope, isolation in ECE and TC and SNT using reference positive 
camel pox antisera (Tantawi et al., 1973; Maysa et al., 1998; El-Said, 2001 and Gabry et al., 2003).

These results revealed the advantages and efficacy of ELISA and prepared peroxidase conjugated antibodies for diagnosis and titration of CPV and agree with those obtained by (Engvall and Perlmann, 1971; Schuurs and Van Weemer, 1977 and Azwai, 1996) who recorded that the peroxidase labeled antibodies are designed to provide maximal assay signal and minimal background in immunoassays such as micro-well ELISA, immunoblotting techniques and they are frequently used in indirect detection assays using labeled secondary antibody. It also can be used for extracting specific antigen from impure mixture. Moreover, it is a preferred method for detecting of unknown antigen even when it is too diluted, as it will be directly absorbed onto the microwell or nitrocellulose membrane surface.

From all above-mentioned results, it could be concluded that the locally prepared labeled CPV antibodies either in rabbits or goats could be used successfully for detection of CPV either vaccinal strains or isolated strains from infected animals. The locally prepared peroxidase conjugates against CPV was also considered cheaper, easier and gave rapid and accurate detection of CPV using various methods of ELISA in comparison to expensive and complicated methods such as electron microscope and virus isolation.

\section{References}

Azwai, S. M.; Carter, S. D.; Woldehiwet, Z. and Wernery, U. (1996): Serology of orthopox-virus cameli infection in dromedary camels: analysis by ELISA and western blotting. Comp., Immunol., Microbiol. Infect. Dis., 19 (1): 65-78.

El-Harrak, M. and Loutfi, C. (2000): Camelpox in dromedary calves in Morocco. Proceedings of the international workshop on the camel calf, Quarzazate, Morocco, 24-26 October 1999, Revue de Levage et de Medicine Vet. Des. Pays. Tropicaux, 53: (2): 165-167.

El-Kabbany, M. M. A.; Kassem, I. K. A. and Kalad, M. A. (2002): Trial for production of diagnostic kit for diagnosis of equine viral diseases. Egypt. J. Agric. Res., 80: 2.

El-Said, A. A. (2001): Trial for production of camel-pox vaccine and evaluation of the product. Ph.D. Thesis, Microbiol., Fac. Vet. Med. Alexandria Univ.

Engvall, E. and Perlmann, P. (1971): Enzyme linked immunosorbent assay (ELISA). Quantitation assay of immunoglobulin-G. Immuno. Chem., 8: 871-874.

Engvall, E. and Perlmann, P. (1972): Enzyme linked immunosorbent assay (ELISA). Quantitation of specific antibodies by enzyme labeled, anti-immunoglobulin in antigen-coated tubes. J. Immunol., 109: 129-135.
Gabry, G.H.; Gaber, A. S. and Eweis, M. (2003): Growth characteristics of camelpox virus and camel contagious ecthyma virus. J. Egypt. Vet. Med. Assoc., 63 (3): 129-139.

Hafez, S.M.; Eissa, E.M.; Amjad, A.M.; Al-Sharif, A.K.; Al-Sukaryan, A. and Cruz, D. (1986): Preliminary studies on camel-pox in Saudi Arabia. Program and abstracts on the $9^{\text {th }}$ Symp. On the biological aspect of Saudi Arabia, Riyadh, pp. 78.

Johann, S. and Czerny, C.P. (1993): A rapid antigen capture ELISA for the detection of orthopox viruses. J. Vet. Med. Series B. 40 (8): 569-581.

Kadden, O. R.; Walz, A.; Czerny, C. P. and Wernery, U. (1992): Progress in the development of camel-pox vaccine. Proc. $1^{\text {st }}$ Int. Camel Conf., Dubai, 2-6 Feb.

Khanna, N. D.; Uppal, U. K.; Sharma, N. and Triparthi, B. N. (1996): Occurrence of pox infections in camels. Indian Vet. J., 73 (8): 813-817.

Martin, W. B.; Ehran, M. and Onar, B. (1975): Studies on sheep pox vaccine, serum-virus neutralization tests. Pendik Veteriner Kontrol Ve Arastirma Enstitusn, Dergisi, 8 (1): 26-47.

Maysa, H. Sh.; Ahmed, M.H.; Salem, S.A. and ElKabbany, M. M. (1998): Some virological and pathological studies on camelpox. Egypt. J. Agric. Res., 76 (4): 1971-1688.

Munz, E. (1992): Pox and pox like diseases in camels. Proc. of the $1^{\text {st }}$ Int. Camel Conf. Edited by Allen W. R.; Higgins, A. J.; Mayhew, I. G.; Snow, D. H. and Wade, J. F. R. and W. Publications Ltd, New market, pp. 43-46.

Munz, E.; Kropp, E.; Pfahler, W. and Reimann, M. (1986a): Detection of antibodies against the orthopox virus cameli in sera of East African dromedaries using two different ELISA nuclear and related techniques in animal production and health. Proc. Symp., Vienna 17-21March, pp., 313-320.

Munz, E.; Kropp, E. M. and Reimann, M. (1986b): Demonstration by ELISA of antibodies against camel orthopox virus in serum samples from East African dromedaries. J. Vet. Med., B. 33 (3): 221-230.

Munz, E.; Otterbein, O. K.; Meyer, H. and RennerMuler I. C. (1997): Laboratory investigations to demonstrate a decreased virulence of two cell adapted African camelpox virus isolates as possible vaccine candidates. J. of Camel Practice and Res., 4 (2): 169-175.

Nakane, P. K. and Kawaoi, A. (1974): Peroxidase labeled antibody: A new method of conjugation. J. Histochem. Cyto., 11: 1084.

Narin, R.C. (1969): Flurescent protein tracing. 2nd Ed. Edinburgh and London Livongstone.

Saad, S.; Zeidan, S.M.; Kassem, I. K. A and Taha, M. M. (2001): Trials for preparation and application of peroxidase conjugated antibodies antigens Rift Valley Fever. J. Egypt. Vet. Med. Assoc., 61 (2): 321-328.

Schuurs, A. H. W. M. and Van Weemer, B. K. (1977): Enzyme immunoassay. Clin. Chimica. Acta. (81): 1-40.

Tantawi, H. H.; Saban, M. S.; Reda, I. M.; Dahaby, H. E. (1973): camelpox virus in Egypt. I- isolation and characterization. Bull. Anim. Hlth. Prod., 22 (4): 315-319.

Tefera, M. and Gebreah, F. (2001): A study on the productivity and diseases of camels in Eastern Ethiopia. Trop. Anim. Hlth. Prod., 33 (4): 265-274.

Tijssen, P. and Kurstak, E. (1984): Highly efficient and simple methods for the peroxidase antibody conjugates for enzyme immunoassay: Analyt. Biochem., 136: 451-457.

Vogt, P. K. (1969): Immunofluorescent detection of viral antigen. Fundamental Techniques in Virology Book. New York, London, pp., 316-326. 
Warnery, U.; Meyer, H. and Pfeffer, M. (1997): Camelpox in the United Arab Emirates and its prevention. J. Camel Practice and Res., v. 4 (2): 135-139.

Wilson, M.B. and Nakane, P.K. (1978): Recent develop- ments in the periodate method of conjugating horseradish peroxidase (HRPO) to antibodies immunofluorescence and related staining techniques. Eds W-Knapp, K. Holubor and G. Wack, Elsevier, North Holland Biomedical Press, Amsterdam. 